\title{
Review of economic data on closed system transfer drug for preparation and administration of hazardous drugs
}

\author{
Annaelle Soubieux, ${ }^{1}$ Cynthia Tanguay $\left(10,{ }^{1}\right.$ Jean Lachaine, ${ }^{2}$ Jean-François Bussières ${ }^{1,2}$
}

${ }^{1}$ Pharmacy practice research unit, CHU Sainte-Justine,

Montreal, Canada

${ }^{2}$ Faculté de pharmacie, Université de Montréal, Montreal, Canada

\section{Correspondence to} Jean-François Bussières, Unité de Recherche en Pratique Pharmaceutique, Département de pharmacie, Centre Hospitalier Universitaire SainteJustine, Montréal, QC H3T 1C5, Canada; jf.bussieres@ssss. gouv.qc.ca

Received 11 October 2018 Revised 14 January 2019 Accepted 22 January 2019 Published Online First

22 February 2019

EAHP Statement 3:

Production and

Compounding.
Check for updates

(C) European Association of Hospital Pharmacists 2020. No commercial re-use. See rights and permissions. Published by BMJ.

To cite: Soubieux A,

Tanguay C, Lachaine J, et al.

Eur J Hosp Pharm

2020:27:361-366

\section{ABSTRACT}

Objectives The objectives of this study were to review economic data on the use of closed system drug transfer devices (CSTDs) for preparing and administering hazardous drugs, and to evaluate the quality of data reporting as defined by the Consolidated Health Economic Evaluation Reporting Standards (CHEERS). Methods All references from a recent Cochrane review about CSTDs were evaluated for inclusion. A literature review was also conducted. Articles containing economic data about the use of CSTDs were retained for analysis. Two researchers independently graded the articles according to the 24-item CHEERS checklist.

Results Of the 138 articles identified initially, 12 were retained for analysis. Nine of these studies did not report acquisition costs or did not detail acquisition costs. Six studies reported economic benefits associated with the used of CSTDs, all related to extending the beyond-use date. The mean number of CHEERS criteria fulfilled by the included articles was 9.2 (SD 2.4).

Conclusions CSTDs are costly to acquire. However, few studies have examined the economic impact of these devices, and the existing studies are incomplete. As a result, hospitals planning to implement these devices will be unable to make a sound economic evaluation. Robust economic evaluation of CSTDs is needed.

\section{INTRODUCTION}

Hazardous drugs are compounds that are carcinogenic or teratogenic, or that present reproductive, organ or genetic toxicity. ${ }^{1}$ Healthcare workers, especially nurses and pharmacy personnel, experience occupational exposure to these hazardous drugs. Various strategies are used to limit surface contamination and workers' exposure, such as using biological safety cabinets, priming intravenous tubing in the pharmacy, using personnel protective devices, and providing training. ${ }^{1}$

Closed system drug transfer devices (CSTDs) can be used for preparing and administering hazardous drugs, in conjunction with other safe handling techniques. These devices create a 'closed' environment that prevents aerosols from escaping. ${ }^{1}$ Although CSTDs provide additional protection, they must be used inside a safety cabinet for the preparation of hazardous drugs. ${ }^{2}$

A recent Cochrane review concluded that there is no high-quality evidence to support (or refute) the routine use of these devices in addition to safe handling. ${ }^{3}$ Even though some studies have shown a reduction in contamination with use of CSTDs, ${ }^{4}$ others have reported lower surface contamination without their use. ${ }^{6}$ Some of these CSTD studies had observation biases and lacked an adequate control group. Many groups have shown a reduction in surface contamination over time, without using CSTDs. ${ }^{78}$ Certain technical flaws have also been reported (eg, spills, trouble handling the devices). ${ }^{9-11}$

A key impediment to use of CSTDs is their high cost. $^{12}$ One hospital estimated a yearly cost of US\$1.5 million to implement CSTDs. ${ }^{12}$ Another centre stopped its participation in a study because of the high acquisition costs. ${ }^{13}$ Yet another centre reported spending $75 \%$ more in implementation costs than what had been estimated by the vendor. ${ }^{14}$ To make an informed decision about CSTDs, healthcare organisations must be able to adequately evaluate the costs involved, especially considering the uncertainty regarding the health benefits for workers.

To date, economic evaluations on the use of CSTDs appear to be incomplete. ${ }^{3}$ The Consolidated Health Economic Evaluation Reporting Standards (CHEERS) can be used to design and evaluate economic data in healthcare settings to ensure adequate reporting of all key variables. ${ }^{15}$

The objectives of this study were to review economic data on the use of CSTDs for preparing and administering hazardous drugs and to evaluate the quality of data reporting as defined by the CHEERS criteria. $^{15}$

\section{METHODS}

\section{Study selection}

All references from the Cochrane study were considered $^{3}$ for inclusion. In addition, a literature review was conducted on 12 March 2018 using the PubMed, CINAHL, HAL, ERUDIT and thèse. fr databases, a cost-effectiveness analysis registry ${ }^{16}$ and the Economic Evaluation Database of the National Health Service (UK). ${ }^{17}$ The following search terms were used: 'closed system transfer device' OR 'CSTD'. A manual search was also conducted.

For articles selected on the basis of initial screening of titles, the full text was read to identify articles relevant for this review. All studies that presented economic data on the use of CSTDs were included, even if economic evaluation was not their main goal. A spreadsheet with the following elements was created: author, year and country of each study, the CSTD evaluated; costs and cost savings; and study limitations. 


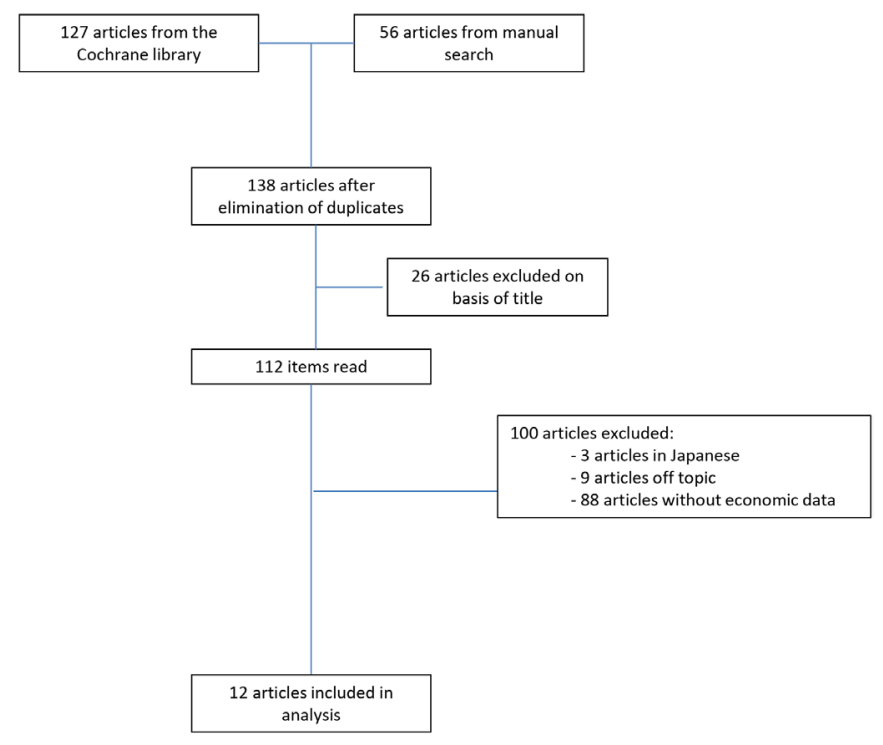

Figure 1 Selection of studies for inclusion in review.

\section{Quality of reporting}

For all included studies, the CHEERS checklist was applied $(n=24$ criteria). For each study, every criterion was reviewed (and categorised as yes, no or not applicable) independently by two members of the research team (AS, CT). Differences were resolved by consensus.

\section{RESULTS}

\section{Economic data on the use of CSTDs}

A total of 12 studies were included (figure 1$)^{101118-27}$ : 10 original articles, one thesis and one poster presentation. Studies were conducted in six countries: USA $(n=4)$, Spain $(n=3)$, France $(n=2)$, Malaysia $(n=1)$, Hungary $(n=1)$ and Turkey $(n=1)$. All but one of the studies took place in a hospital setting; the single exception was conducted in a veterinary setting. ${ }^{23}$ The PhaSeal device (Becton Dickinson) was the CSTD most frequently evaluated (in nine of the 12 studies).

Six of the studies presented economic data about preparing and administering hazardous drugs, four examined the costs of preparation only, and two did not provide details of the economic evaluation.

Two studies presented actual costs (table 1), six showed estimated costs (table 2), and four used a combination of actual and estimated costs (table 3 ). Five studies concluded that there were cost savings associated with using CSTDs, whereas seven showed that costs increased. Among the five studies that reported cost savings, two did not calculate the acquisition costs. Notably, acquisition cost was the direct cost that was most frequently evaluated $(n=10)$. However, seven of these studies did not provide detailed itemisation of costs. Other direct costs included workers' time $(n=2)$ and drug costs $(n=5)$. One study evaluated the additional waste generated by the CSTDs, ${ }^{10}$ and another evaluated the cost of drugs lost in the 'dead space' of these devices. ${ }^{18}$ Of the eight studies evaluating the costs, four did not detail costs per dose prepared (CSTDs or conventional system). Six studies evaluated cost savings in terms of being able to extend the beyond-use date beyond that specified by US Pharmacopoeia standards (from 6 hours to 7 days), hypothesising that the CSTD could prolong sterility up to 7 days.

\section{Quality of reporting}

Two studies were excluded from the CHEERS analysis: the poster presentation, which lacked detailed results, ${ }^{19}$ and one study that contained only a brief mention of costs and no formal economic evaluation. ${ }^{20}$ Among the remaining 10 studies, the mean number of CHEERS criteria fulfilled was 9.2 (SD 2.4) out of 24. The maximum number of criteria observed in a single study was 12 . In most studies, key elements were lacking, notably an abstract with structured economic data, a control group (or details about selection of controls), the study perspective, the choice of outcome measures and their efficacy, an uncertainty analysis, and sources of funding (figure 2). None of the studies included a sensitivity analysis. In only four studies did the authors declare no conflicts of interest; five others declared conflicts of interests related to the manufacturers, and three studies failed to mention potential conflicts.

\section{DISCUSSION \\ CSTD costs}

Only 12 studies that presented results on costs associated with the use of CSTDs were found, and all were of low quality. This dearth of data is unfortunate, considering the high costs of these devices. In addition, no study presented a thorough economic evaluation that met most or all of the CHEERS criteria, and key results were lacking from all of the studies.

Only one study took into account actual acquisition costs. Actual acquisition costs ranged between $\$ 15.73$ and $\$ 24.09$ per dose. However, costs were not detailed, and acquisition costs were often the only costs used. In four of the eight studies evaluating the costs, the costs per dose were not detailed. The number of preparations varied from one hospital to another, so cost per dose is probably the most relevant outcome for readers to position themselves on

Table 1 Economic data on closed system drug transfer devices from studies that reported actual costs

\begin{tabular}{|c|c|c|c|c|c|c|c|}
\hline \multirow[b]{2}{*}{ Reference } & \multirow[b]{2}{*}{ CSTD } & \multicolumn{2}{|l|}{ Costs } & \multicolumn{2}{|l|}{ Cost savings } & \multirow{2}{*}{$\begin{array}{l}\text { CHEERS } \\
\text { criteria }\end{array}$} & \multirow[b]{2}{*}{ Limitations } \\
\hline & & Type & Values & Type & Values & & \\
\hline $\begin{array}{l}\text { Ozyaman (2016) } \\
\text { Turkey }^{19}\end{array}$ & $\begin{array}{l}\text { PhaSeal } \\
\text { (compared with } \\
\text { conventional system) }\end{array}$ & Not evaluated & Not evaluated & $\begin{array}{l}\text { Extension of } \\
\text { BUD }\end{array}$ & $\begin{array}{l}€ 36137 / \\
3 \text { months }\end{array}$ & NA & $\begin{array}{l}\text { Acquisition costs not evaluated. } \\
\text { Partial data reported (as a poster). }\end{array}$ \\
\hline $\begin{array}{l}\text { Kicenuik et al } \\
(2017) \\
\text { USA }^{23}\end{array}$ & $\begin{array}{l}\text { Equashield } \\
\text { PhaSeal } \\
\text { (compared with } \\
\text { conventional system) }\end{array}$ & $\begin{array}{l}\text { Acquisition costs, } \\
\text { administration time }\end{array}$ & $\begin{array}{l}\text { Equashield: } \\
\text { US\$15.73/dose } \\
24 \text { s/dose } \\
\text { PhaSeal: } \\
\text { US\$24.09/dose } \\
29.1 \text { s/dose } \\
\text { Conventional: } \\
26.9 \text { s/dose }\end{array}$ & Not evaluated & Not evaluated & $12 / 24$ & $\begin{array}{l}\text { Phaseal sold by the unit and } \\
\text { Equashield sold in bulk. } \\
\text { Simulated administrations. } \\
\text { Acquisition costs not evaluated for } \\
\text { conventional system. } \\
\text { Conflicts of interest: } \\
\text { CSTDs provided free of charge by the } \\
\text { manufacturers. }\end{array}$ \\
\hline
\end{tabular}




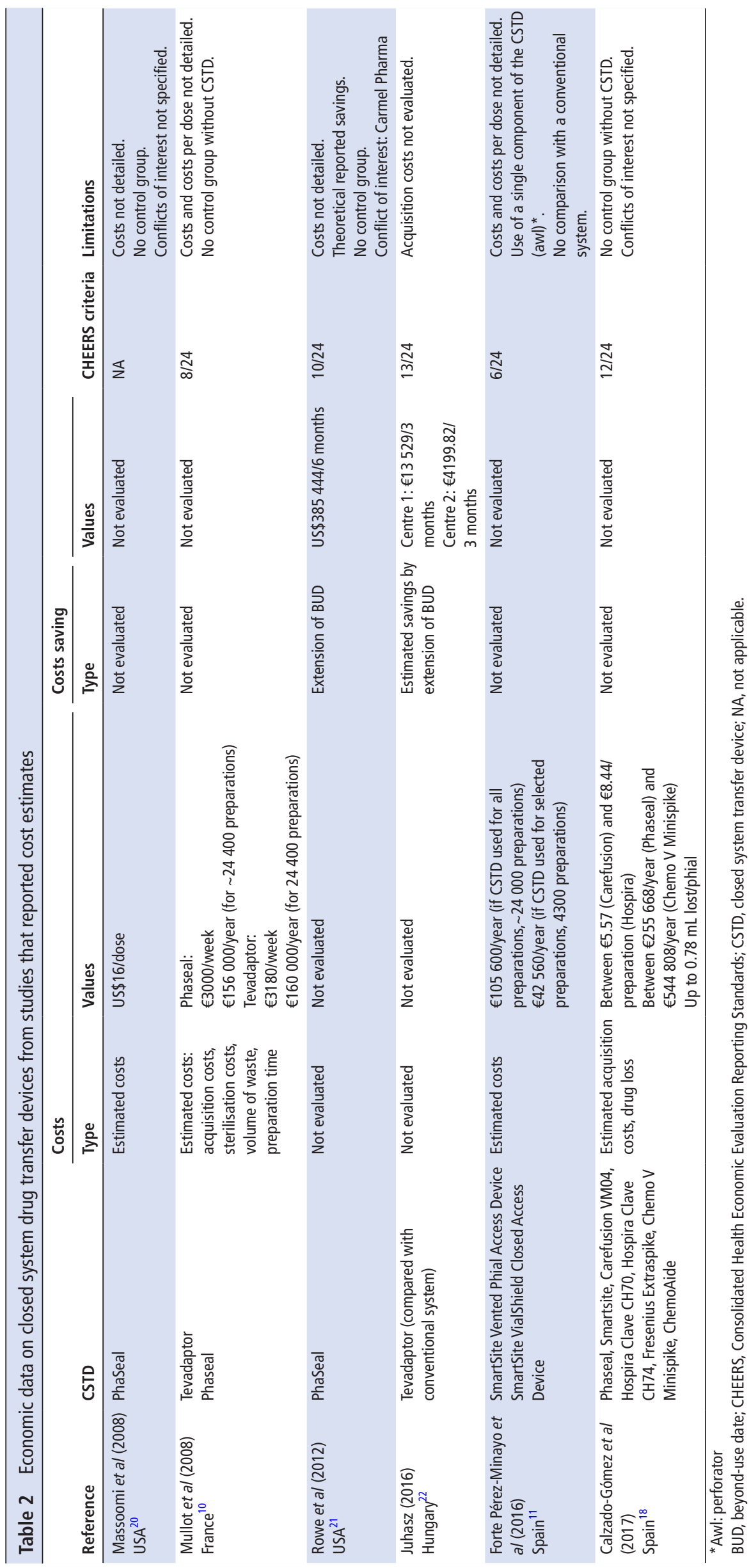


Table 3 Economic data on closed system drug transfer devices from studies that reported both actual and estimated costs

\begin{tabular}{|c|c|c|c|c|c|c|c|}
\hline \multirow[b]{2}{*}{ Reference } & \multirow[b]{2}{*}{ CSTD } & \multicolumn{2}{|l|}{ Costs } & \multicolumn{2}{|c|}{ Costs saving } & \multirow{2}{*}{$\begin{array}{l}\text { CHEERS } \\
\text { criteria }\end{array}$} & \multirow[b]{2}{*}{ Limitations } \\
\hline & & Type & Values & Type & Values & & \\
\hline $\begin{array}{l}\text { Edward et al } \\
(2013) \\
\text { USA }^{24}\end{array}$ & Phaseal & Acquisition cost & US\$106 557/year & $\begin{array}{l}\text { Extension } \\
\text { of BUD } \\
\text { Estimated } \\
\text { annual cost }\end{array}$ & $\begin{array}{l}\text { US\$96 } 349 \\
150 \text { days } \\
\text { US\$703 } 047 \\
\text { lyear } \\
\text { The average waste } \\
\text { avoidance per phial } \\
\text { was } 29 \%\end{array}$ & $10 / 24$ & $\begin{array}{l}\text { Acquisition costs and } \\
\text { costs per dose not } \\
\text { detailed. } \\
\text { Conventional system: } \\
\text { drugs discarded } \\
\text { immediately after first } \\
\text { use (overestimates } \\
\text { savings). } \\
\text { Conflicts of interest: } \\
\text { funding from Celgene, } \\
\text { Millennium and } \\
\text { Seattle Genetics. }\end{array}$ \\
\hline $\begin{array}{l}\text { Barny et al } 2015 \\
\text { France }^{25}\end{array}$ & $\begin{array}{l}\text { Phaseal (compared } \\
\text { with conventional } \\
\text { system) }\end{array}$ & $\begin{array}{l}\text { Acquisition costs, } \\
\text { preparation time, } \\
\text { ganciclovir costs }\end{array}$ & $\begin{array}{l}\text { Phaseal: } € 39.04 \pm 37.26 \\
\text { /preparation } \\
\text { Conventional system: } \\
€ 34.19 \pm 11.39 / \text { preparation }\end{array}$ & $\begin{array}{l}\text { Estimated } \\
\text { savings by } \\
\text { extension } \\
\text { of BUD }\end{array}$ & $\begin{array}{l}€ 4.62 \text { ( } 2 \text { days } \\
\text { extension) €11.64/ } \\
\text { preparation ( } 7 \text { days } \\
\text { extension), }\end{array}$ & $10 / 24$ & $\begin{array}{l}\text { Costs not detailed. } \\
\text { Conflict of interest: } \\
\text { thanks to Becton } \\
\text { Dickinson. }\end{array}$ \\
\hline $\begin{array}{l}\text { González-Haba et } \\
\text { al } 2016 \\
\text { Spain }^{29}\end{array}$ & $\begin{array}{l}\text { ChemoClave } \\
\text { (eight combinations } \\
\text { tested) }\end{array}$ & $\begin{array}{l}\text { Acquisition costs, } \\
\text { preparation time, } \\
\text { estimated annual cost }\end{array}$ & $\begin{array}{l}\text { Between } € 4.46 \text { and } € 8.52 / \text { dose } \\
\text { Between } 41.0 \text { and } 77.0 \text { s/dose } \\
€ 300000 / \text { year }\end{array}$ & $\begin{array}{l}\text { Estimated } \\
\text { savings } \\
\text { if not all } \\
\text { parts of the } \\
\text { system are } \\
\text { used }\end{array}$ & $\begin{array}{l}€ 1.03 / \text { dose } \\
€ 39069 / \text { year }\end{array}$ & $6 / 24$ & $\begin{array}{l}\text { Acquisition costs not } \\
\text { detailed. } \\
\text { No control group } \\
\text { without CSTD. } \\
\text { Simulated } \\
\text { preparations. } \\
\text { Conflicts of interest } \\
\text { not specified. }\end{array}$ \\
\hline $\begin{array}{l}\text { Chan et al } 2016 \\
\text { Malaysia }^{26}\end{array}$ & $\begin{array}{l}\text { Phaseal (compared } \\
\text { with conventional } \\
\text { system) }\end{array}$ & $\begin{array}{l}\text { Acquisition costs (CSTD } \\
\text { +other consumables), } \\
\text { drug costs, estimated } \\
\text { cost per dose, estimated } \\
\text { annual cost } \\
\text { Estimated costs for } \\
\text { conventional system. }\end{array}$ & $\begin{array}{l}\text { Phaseal: } \\
\text { US\$92072/3 months } \\
\text { US } \$ 23106 / 3 \text { months } \\
\text { (acquisition costs only) } \\
\text { US } \$ 40.92 / \text { preparation } \\
\text { US } \$ 368289 / \text { year } \\
\text { Conventional system: } \\
\text { US } \$ 83155 / 3 \text { months } \\
\text { US } \$ 6988 / 3 \text { months } \\
\text { (acquisition costs only) }\end{array}$ & $\begin{array}{l}\text { Extension } \\
\text { of BUD }\end{array}$ & $10.5 \%$ of drug costs & $11 / 24$ & $\begin{array}{l}\text { Costs per dose for } \\
\text { conventional system } \\
\text { not detailed. } \\
\text { Conflict of interest: } \\
\text { Becton Dickinson } \\
\text { provided information. }\end{array}$ \\
\hline
\end{tabular}

BUD, beyond-use date; CHEERS, Consolidated Health Economic Evaluation Reporting Standards; CSTD, closed system transfer device.

the economic impact of CSTDs in their hospital. Economic evaluations on the use of CSTDs should also consider storage, elimination of waste, ${ }^{14}$ implementation and training time, and the quantity of drugs lost in the devices.

\section{COST SAVINGS}

There was marked inconsistency in the conclusions: some studies presented high costs, and others reported important cost savings. The savings were based mainly on extending the beyond-use date. The US Pharmacopoeia requires a preparation to be used within 6 hours. Some authors claim that using a CSTD can preserve the sterility and that preparations can be kept for up to 7 days. ${ }^{21} 28$ Studies supporting this claim have methodological flaws and lack a control group to evaluate the level of contamination when compounding without CSTD. It could be argued that the sterility of most antineoplastic drug preparations would be kept when compounded in a biological safety cabinet by a properly trained technician. For instance, Rowe et $\mathrm{al}^{21}$ found that $1.86 \%$ of samples were contaminated, but attributed this to an outside contamination. No tests were conducted without using a CSTD. In addition, cost savings were mostly theoretical and failed to take into account that the entire volume of a phial would not necessarily be used in the 7 days following its preparation.

\section{Quality of reporting}

The majority of the CHEERS criteria were not reported. In the included studies, the reported methods for calculating costs lacked details, and cost data were incomplete. Future studies should detail all costs (and cost savings) to allow generalisation and reproducibility. Sensitivity analyses should also be conducted. Authors of future studies are encouraged to review the CHEERS checklist to improve the quality of the results reported; the criteria should also be reviewed when designing the study. In addition to comparing several CSTDs, authors should make sure to include the costs of the conventional system for preparing and administering hazardous drugs and determine the quantity of devices needed per dose and overall. None of the included studies involved a formal economic evaluation. Such a study should also be free from any conflict of interest. Ideally, economic studies should also include efficacy criteria. Although the US Pharmacopoeia ${ }^{2}$ recommends use of CSTDs for the administration of hazardous drugs, this organisation also emphasises that there is no guarantee that all CSTDs will perform adequately. A performance protocol for CSTDs is needed, in addition to well conducted studies designed to evaluate if their use can lead to measurable health benefits for workers.

A centre looking to implement CSTDs should critically review the literature to support their choice. It should first include an evaluation of their current working practices to identify other safe handling practices that could be applied. It is recommended that environmental monitoring is performed twice per year to identify the current state of surface contamination; it would be ideal to have at least 1 year of data before implementing a change to avoid confusing the effect of an increase in workers' awareness with the effect of the change implemented. Centres should make sure that 


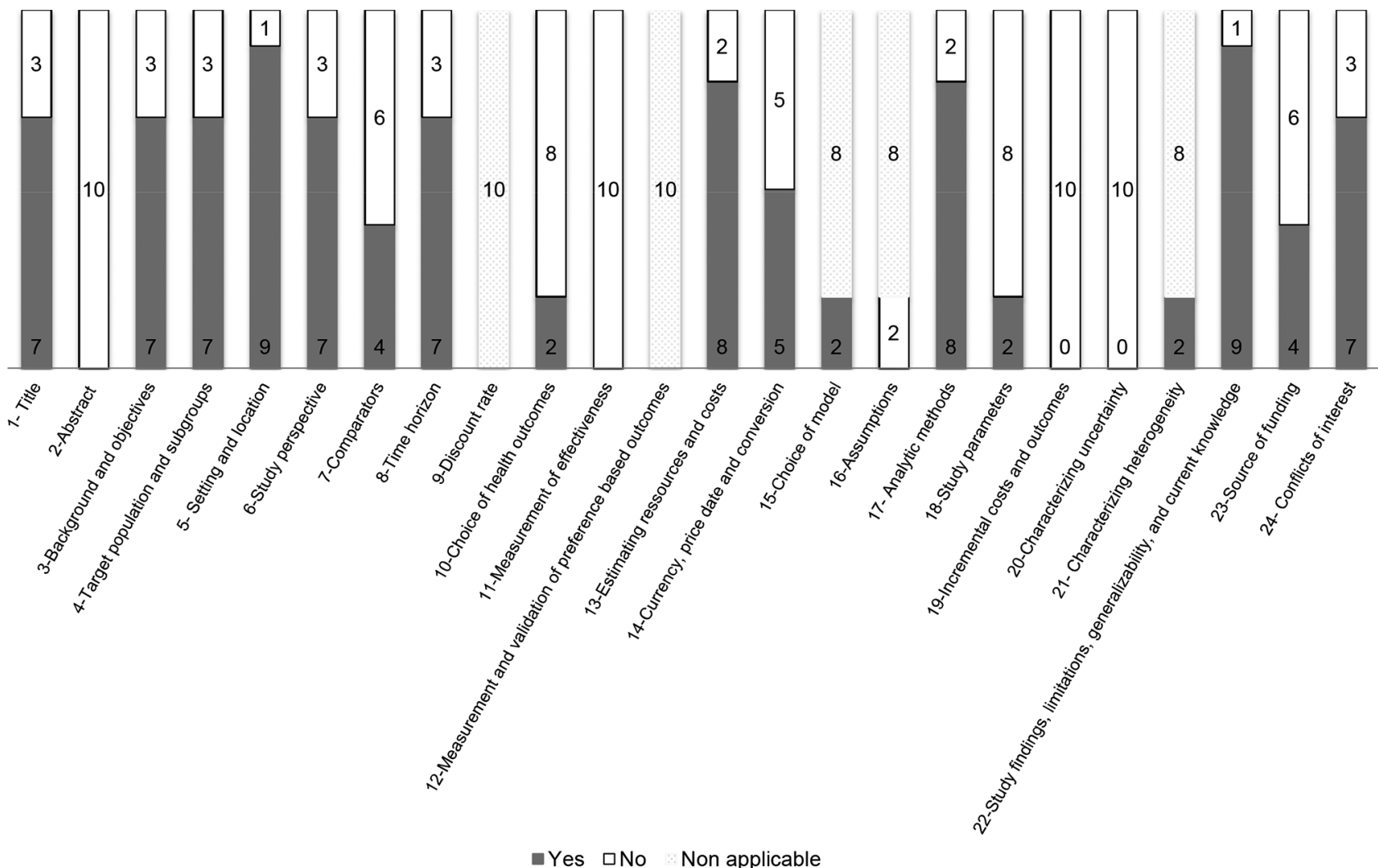

Figure 2 Evaluation of study quality according to CHEERS tool (Consolidated Health Economic Evaluation Reporting Standards), with data presented as number of studies meeting each criterion.

they consider all costs incurred, which in addition to acquisition costs include additional workload, training resources, storage, incineration of material and potential drug loss in the device.

\section{Strengths and limitations}

Two authors independently rated the studies according to the CHEERS checklist. Given the general lack of economic data in the literature, we included all studies that presented costs, even though none of the included studies presented a formal economic evaluation. In the CHEERS analysis, we rated a criterion as 'present' if the study fulfilled any aspect (not necessarily all aspects) of the relevant

What is already known on this subject

- There is no high-quality evidence to support (or refute) the routine use of closed system drug transfer devices (CSTDs) in addition to safe handling regarding the reduction of surface contamination.

- In a context of budgetary constraints, economic evaluation of the use of CSTDs appears to be incomplete.

- CSTDs are an expensive technology.

What this study adds

- This is the first review of the literature on the economic data of CSTDs and evaluation of the quality of data reporting as defined by the Consolidated Health Economic Evaluation Reporting Standards (CHEERS) criteria.

- This literature review identified a lack of properly conducted economic evaluations of CSTDs, despite their high acquisition costs.
CHEERS statement (ie, minimal level). Even so, the CHEERS scores were low, and the analysis was conservative.

\section{CONCLUSIONS}

This literature review identified a lack of properly conducted economic evaluations of CSTDs, despite their high acquisition costs. As a result, hospitals that are considering implementation of these devices will be unable to make a sound and informed decision.

We advocate for a robust and complete economic evaluation of the use of CSTDs for the preparation and administration of hazardous drugs.

Funding The authors have not declared a specific grant for this research from any funding agency in the public, commercial or not-for-profit sectors.

Competing interests None declared.

Patient consent for publication Not required.

Provenance and peer review Not commissioned; externally peer reviewed.

ORCID iD

Cynthia Tanguay http://orcid.org/0000-0003-0969-6051

\section{REFERENCES}

1 National Institute for Occupational Safety and Health, 2004. Preventing occupational exposures to antineoplastic and other hazardous drugs in health care setting. Available: https://www.cdc.gov/niosh/docs/2004-165/pdfs/2004-165.pdf [Accessed 10 Apr 2018].

2 US Pharmacopeial Convention (USP), 2017. General chapter <800> Hazardous drugs - handling in healthcare settings. Available: http://www.usp.org/sites/default/files/usp/ document/our-work/healthcare-quality-safety/general-chapter-800.pdf [Accessed 10 Apr 2018]

3 Gurusamy KS, Best LM, Tanguay C, et al. Closed-system drug-transfer devices in addition to safe handling of hazardous drugs versus safe handling alone for reducing healthcare staff exposure to infusional hazardous drugs, 2018. 
4 Harrison BR, Peters BG, Bing MR. Comparison of surface contamination with cyclophosphamide and fluorouracil using a closed-system drug transfer device versus standard preparation techniques. Am J Health Syst Pharm 2006;63:1736-44.

5 Sessink PJ, Connor TH, Jorgenson JA, et al. Reduction in surface contamination with antineoplastic drugs in 22 hospital pharmacies in the US following implementation of a closed-system drug transfer device. J Oncol Pharm Pract 2011;17:39-48.

6 Poupeau C, Tanguay C, Caron NJ, et al. Multicenter study of environmental contamination with cyclophosphamide, ifosfamide, and methotrexate in 48 Canadian hospitals. J Oncol Pharm Pract 2018;24:9-17

7 Sottani C, Porro B, Comelli M, et al. An analysis to study trends in occupational exposure to antineoplastic drugs among health care workers. Journal of Chromatography B 2010;878:2593-605.

8 Chauchat L, Tanguay C, Caron NJ, et al. Surface contamination with ten antineoplastic drugs in 83 Canadian centers. J Oncol Pharm Pract Off Publ Int Soc Oncol Pharm Pract 2018:1078155218773862.

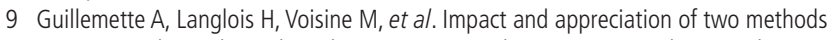
aiming at reducing hazardous drug environmental contamination: the centralization of the priming of IV tubing in the pharmacy and use of a closed-system transfer device. J Oncol Pharm Pract 2014;20:426-32.

10 Mullot H, Blondeel S, Escalup L, et al. Intérêt et faisabilité des systèmes Tevadaptor® et Phasea| $\circledast$ dans une unité centralisée de préparation des anticancéreux. Pharm Hosp 2008;43:189-99.

11 Forte Pérez-Minayo M, Castillo Bazán E, Hernández Segurado M, et al. Use of closed systems in the hospital pharmacy. Farm Hosp Organo Of Expresion Cient Soc Espanola Farm Hosp 2016;40:102-10.

12 Furlow B. How to improve the safety of chemotherapy administration. Oncol Nurse Advis 2010:21-5.

13 Siderov J, Kirsa S, McLauchlan R. Reducing workplace cytotoxic surface contamination using a closed-system drug transfer device. J Oncol Pharm Pract 2010;16:19-25.

14 Lowry F. Closed-System transfer devices lessen worker Contamination —at a cost. Pharm Pract News 2009;36.

15 Husereau D, Drummond M, Petrou S, et al. Consolidated Health Economic Evaluation Reporting Standards (CHEERS)--explanation and elaboration: a report of the ISPOR Health Economic Evaluation Publication Guidelines Good Reporting Practices Task Force. Value Health 2013:16:231-50

16 Center for Evaluation of Value and Risk in Health. Cost-effectiveness analysis registry. Available: http://healtheconomics.tuftsmedicalcenter.org/cear4/SearchingtheCEAR egistry/SearchtheCEARegistry.aspx [Accessed 11 Jul 2018].
17 University of York - NHS EED. Available: https://www.crd.york.ac.uk/CRDWeb/ ResultsPage.asp [Accessed 11 Jul 2018].

18 Calzado-Gómez G, Nazco-Casariego GJ, Viña-Romero MM, et al. Cost-effectiveness study of closed system transfer devices for the preparation of antineoplastic agents. Farm Hosp Organo Of Expresion Cient Soc Espanola Farm Hosp 2017;41:575-82.

19 Ozyaman A, Birli E, Sarikaya MA. PP-018 Drug savings realised by use of a right closed system transfer device in the preparation of antineoplastic drugs. Eur J Hosp Pharm 2016:23(Suppl 1):A202.

20 Massoomi F, Neff B, Pick A, et al. Implementation of a safety program for handling hazardous drugs in a community hospital. Am J Health-Syst Pharm AJHP Off J Am Soc Health-Syst Pharm 2008;65:861-5.

21 Rowe EC, Savage SW, Rutala WA, et al. Economic and microbiologic evaluation of single-dose vial extension for hazardous drugs. J Oncol Pract 2012;8:e45-9.

22 Á J, Batka G, Szücs A. Responding to drug shortages and rising costs: IV chemotherapy drug use optimization achieved by closed safety devices in hospital pharmacies. Drugs Ther Perspect 2016;32:170-6.

23 Kicenuik K, Northrup N, Dawson A, et al. Treatment time, ease of use and cost associated with use of Equashield ${ }^{\top M}$, PhaSeal ${ }^{\circledR}$, or no closed system transfer device for administration of cancer chemotherapy to a dog model. Vet Comp Oncol 2017; 15:163-73.

24 Edwards MS, Solimando DA, Grollman FR, et al. Cost savings realized by use of the PhaSeal $\circledast$ closed-system transfer device for preparation of antineoplastic agents. J Oncol Pharm Pract Off Publ Int Soc Oncol Pharm Pract 2013;19:338-47.

25 Barny M, Blond ML. Economic evaluation of a closed-system drug transfer device for the preparation of IV ganciclovir within care units. Available: https://dumas.ccsd.cnrs. fr/dumas-01205347/document [Accessed 10 Apr 2018].

26 Chan HK, Lim YM. Cost analysis of using a Closed-System transfer device (CSTD) for antineoplastic drug preparation in a Malaysian Government-Funded Hospital. Asian Pac J Cancer Prev APJCP 2016;17:4951-7.

27 Gonzalez R, Massoomi FF. Manufacturers' recommendations for handling spilled hazardous drugs. Am J Health Syst Pharm 2010;67:1985-6.

28 González-Haba Peña E, Manrique Rodríguez S, Herranz Alonso AM, et al. Comparative study of preparation of hazardous drugs with different closed-system drug transfer devices by means of simulation with fluorescein. Farm Hosp Organo Of Expresion Cient Soc Espanola Farm Hosp 2016;40:496-503.

29 De Prijck K, D'Haese E, Vandenbroucke J, et al. Microbiological challenge of four protective devices for the reconstitution of cytotoxic agents. Lett App/ Microbiol 2008:47:543-8. 